http://doi.org/10.35784/iapgos.2707

\title{
USING STEALTH TECHNOLOGIES IN MOBILE ROBOTIC COMPLEXES AND METHODS OF DETECTION OF LOW-SIGHTED OBJECTS
}

\author{
Andrii Rudyk ${ }^{1}$, Andriy Semenov ${ }^{2}$, Olena Semenova ${ }^{2}$, Sergey Kakovkin ${ }^{2}$ \\ ${ }^{1}$ National University of Water and Environmental Engineering, Department of Automation, Electrical Engineering and Computer-Integrated Technologies, Rivne Ukraine, \\ ${ }^{2}$ Vinnytsia National Technical University, Faculty of Infocommunications, Radio Electronics and Nanosystems, Vinnytsia, Ukraine
}

\begin{abstract}
The paper outlines the latest technologies used by the world's leading manufacturers in the development of mobile low-observable robotic systems and promising measures to improve the quality of components and design of such objects. Methods of detecting objects using stealth technologies are considered, and it is shown that only due to a system approach it is possible to compensate for the reduction of the effective scattering surface of low-observable objects by technical means of radar stations. It is shown that the main method of increasing the range to the radio horizont is the use of an air-based radar. Methods of detecting objects on the traces of their interaction with the environment are promising for organization of cooperation of several radars in the detection of low-observable objects.
\end{abstract}

Keywords: stealth technologies, mobile robotic complex, low-observable object, radar station, detection methods, signal-to-noise ratio

\section{WYKORZYSTANIE TECHNOLOGII STEALTH W MOBILNYCH ZESPOLACH ROBOTYCZNYCH ORAZ METODY WYKRYWANIA NIEWIDOCZNYCH OBIEKTÓW}

Streszczenie. $W$ artykule przedstawiono najnowsze technologie stosowane przez wiodacych światowych producentów w rozwoju mobilnych systemów robotycznych o niskiej obserwowalności oraz obiecujace działania majace na celu poprawe jakości komponentów i konstrukcji takich obiektów. Rozważono metody wykrywania obiektów wykorzystujace technologie stealth $i$ wykazano, że tylko dzięki podejściu systemowemu możliwa jest kompensacja zmniejszenia efektywnej powierzchni rozpraszania obiektów słabo obserwowalnych przez stacje radarowe. Wykazano, że główna metoda zwiększenia zasięgu do poziomu radiowego jest użycie radaru lotniczego. Metody wykrywania obiektów na podstawie śladów ich interakcji z otoczeniem sa obiecujace w wykrywaniu obiektów słabo obserwowalnych przy wspótpracy kilku radarów.

Słowa kluczowe: technologie stealth, mobilny kompleks robotów, obiekt niepozorny, stacja radiolokacyjna, metody detekcji, stosunek sygnału do szumu

\section{Introduction}

Stealth technologies are a complex of technical solutions; their application reduces the level of signals from an object to receiving devices of an object detection system. The stealth technologies are effectively used in objects that belong to the class of lowobservable objects. Designing the low-observable objects is the result of a scientific and technological breakthrough in expensive scientific and highly efficient technologies and is the property of mostly economically highly developed countries, whose doctrines are based on a guaranteed military and technical superiority over other countries.

\section{Main directions of using and designing the low-observable means}

Nowadays, there are three main directions in aircraft, shipbuilding, mechanical engineering and mobile robotics of applying low-observable means [18]:

- the maximum possible introduction of stealth technologies for objects to be constructed and designed;

- application of single "invisibility" elements, caused by the lack of sufficient funding (in most cases, the anti-radar coverage and some other elements of full-fledged stealth technology are rejected);

- design and manufacture of small low-observable means (mobile robots), which can be utilized for operating on enemy's territory.

Main scientific and technical directions of modern stealth technologies are a theory of diffraction on complex objects and production and investigation of radiation-absorbent materials. Development of stealth technology begins with a mathematical modeling of electromagnetic wave scattering on an object whose radar visibility is to be reduced. This stage is essential for preliminary evaluation of a possible result and allows optimizing a shape and electrophysical characteristics of the object. Mathematical models are based on the boundary value problems for the electromagnetic wave diffraction on objects of complex shape, which include special materials. A modern computer technique allows creating software to simulate the electromagnetic wave scattering on complex objects like aircrafts and ships, regarding a large number of equipment, cracks, hatches and other details. Such modeling yields an architecture of the object with shapes that satisfy the invisibility conditions. A low visibility of the object can be achieved by choosing the architecture due to the fact that a radar signal, like a light ray, propagates in a straight line according to the geometric optics laws. This means that the object architecture must be chosen to prevent the signal reflection in the direction of the radar receiving antenna caused by the reflection in other directions. Dimensions of signal reflection surfaces must be much larger than the wavelength of a radar signal, this provides its reflection from a mobile object surface. The radar signal scattered on the whole surface must be formed in a special way in order to place the instantaneous equivalent center of the object out of its geometric dimensions. This complicates the radio-locating steering when attacking a mobile object.

\section{Creation of the newest materials for MR cases}

A crucial factor in invisibility is the material of the MR case. Leading research laboratories create substances and materials with specified properties of real and imaginary parts of the dielectric constant in a required frequency range. However, similar studies in the creation of substances with the given law of magnetic permeability change in a certain frequency range are difficult in practical implementation.

Emergence of mobile robotic complexes (MRCs) with a wide range of action required the creation of new materials and technologies of their production for implementation in created samples of MRCs [12].

Development of the MRCs is one of the key priorities for technical modernization of the country's military. New materials and production technologies for development of new models of MRCs promote technical modernization and updating of manufacturing.

In development of electromagnetic wave absorbers, various materials are used having a property of absorbing electromagnetic radiation in a certain frequency range. The ability of a medium to absorb electromagnetic radiation is determined by its electrical and magnetic properties, namely the specific electrical conductivity and dielectric and magnetic permeability. These characteristics are used to describe a process of electromagnetic wave propagation and are generally nonlinear, tensor or complex quantities. 
Absorption of electromagnetic energy occurs due to dielectric and magnetic losses, and losses on conductivity, which must be maximized to achieve maximal shielding efficiency. However, when electromagnetic waves fall on a material, there is a reflection from the boundary. The greater is the difference in the impedance of the media, the greater is the magnitude of the reflection coefficient.

When creating broadband absorbing coatings (BAC), the main problem is to harmonize the absorbing structure with the environment, i.e. to minimize the integrated effect of reflection.

There are several ways to reduce the reflection of monochromatic electromagnetic waves from conductive (reflective) surfaces.

The simplest way to reduce the reflection effect is a resonant type of radiation-absorbent material (RAM), which is based on the Salisbury screen principle. A layer (thin film) of absorbent (conductive) material is located at the distance $\lambda / 4$ in front of the conductive surface. The incident energy of high-frequency radiation is reflected from the outer and inner surfaces of the RAM and an interference pattern of neutralization (suppression) of the incident wave is formed. Another design of the electromagnetic wave absorber is an absorber consisting of a layer of RAM with a matching quarter-wave layer of non-absorbing material in front of it. However, the absorber operates effectively only at a fixed frequency and with a normal incidence of the wave on the conductive surface, so this method is of little practical use.

Another way to reduce the reflection is based on the fact that the wave resistance of a non-conductive material is determined by the ratio $Z=\sqrt{\mu_{a} / \varepsilon_{a}}$, where $\mu_{a}$ and $\varepsilon_{a}-$ are the absolute magnetic and dielectric permeability of the non-conductive material respectively. A impedance $Z$ equal to the resistance of free space can be obtained by choosing the required ratio of these parameters.

If hysteresis loops for $\mu_{a}$ and $\varepsilon_{a}$ are the same, i.e. such that for any pair of electric and magnetic field strengths the ratio $\mu_{a} / \varepsilon_{a}$ is the same, then the layer of such absorbing material for the incident wave in the case of a normal falling will be identical by its characteristics to free space.

Electromagnetic wave absorbers can be divided into the following types according to their operation principle [3]:

- interferencial, they apply the principle of mutual quenching the electromagnetic waves superimposed on the antiphase of incident and reflected waves;

- scattering, with the reduction of reflected energy in one direction related with scattering in other directions at different angles;

- absorbing, based on the conversion of electromagnetic wave energy into other types of energy (usually into thermal energy due to the presence of dielectric and magnetic losses of a material);

- combined, they combine different principles of operation in one absorber.

When developing single-layer broadband absorbers of electromagnetic radiation of the absorbing type, magnetodielectrics are usually utilized. For these magnetodielectrics a slight difference between characteristic resistances of the absorber of electromagnetic radiation and free space can be provided by selecting close values of relative dielectric and magnetic permeability. Moreover, an effective absorption can be provided due to large losses.

Futhermore, in [17] inhomogeneous absorbing materials were considered, in which the relative dielectric and magnetic permeability smoothly (for gradient materials) or stepwise (for multilayer structures) varied from values close to 1 on the outer surface to values that provided the desired level of absorbing an electromagnetic wave. This gradual change is achieved either by changing properties of the material, or by changing its geometric shape, that is performed in foam pyramids with carbon filling. Such absorbers usually have a relatively large bandwidth with a small value of the reflection coefficient and a small thickness of the absorber. But, it is difficult to implement them practically. An advantage of the gradient materials compared to the multilayer ones is no reflection at the boundary between the layers.

Single-layer materials with special frequency dependences of complex dielectric constant, multilayer and gradient materials are quite promising for development of dielectric absorbers with a wide operating frequency range.

Dielectric-based RAMs, such as carbon-filled plastics, have a relatively low density, while the coating thickness must be significant. To reduce the power of an incident wave by $20 \mathrm{~dB}$ and $30 \mathrm{~dB}$, the coating thickness is determined by the following ratios:

$$
D_{20 d B}=\frac{0.279}{f \cdot \varepsilon}, \quad D_{30 d B}=\frac{1.65}{f \cdot \varepsilon},
$$

where $f$-is the frequency, $\varepsilon$ - is the dielectric constant.

Advantages of using ferrites with high magnetic permeability as thin-layer absorbers are a small layer thickness and a slight increase in the upper frequency of the operating range at a large layer thickness; the disadvantage is limitation of the operating range by low frequencies [17]. The advantage of ferrites with low magnetic permeability is that the lower limit of the operating frequency range is determined only by a position of the gyromagnetic resonance frequency, and the disadvantage is a large layer thickness required and a strong offset of the upper limit of the frequency range.

Developers pay great attention to RAM based on composite materials, in particular ferritresin mixtures with short metal fibers. Introduction of fibers in the amount of $1 \%$ to $3 \%$ of the mixture weight allows changing the dielectric constant in a wide range. To achieve unique features in the microwave range, materials with conductive inclusions of complex shape are used. They are: open and closed conductive rings, omega particles, single and bi-helixes, dielectric inclusions of various shapes with a high dielectric constant.

Also, RAM and structures based on resistive filaments located in a dielectric matrix are quite common [5]. The resistive filament is a multicomponent fiber with an electrically conductive composite inside it. The leading filler is carbon black with particles of size $(30 \ldots 60) \mathrm{nm}$ containing graphite crystals. The thread sheath has high strength, moisture-resistance and temperature characteristics.

Experimental studies of spectra of magnetic and dielectric permeability and absorption properties of composites performed in [13] showed that composite materials on carbonyl iron had high absorption properties in the frequency range $(3 \ldots 37) \mathrm{GHz}$ at a small thickness of the layer. They can be utilized both as masking coatings on a metal surface and as protective nonreflective coatings with small values of reflection and transmission coefficients. The presence of a minimum reflection coefficient from a two-layer structure at frequencies above $37 \mathrm{GHz}$ provides developing RAM for higher frequencies at an appropriate choice of the layer thickness.

In [10] nanostructured composite RAMs on a polymer basis were considered. They are capable to absorb electromagnetic radiation in a wide range of frequency and power and have a low cost. Moreover, to achieve maximal radiation-absorbing properties, they must meet the following conditions:

- the presence of a developed electrically conductive nanowire in the polymer matrix;

- the presence of nanoparticles of magnetic matter isolated from each other;

- providing additional attenuation of the electromagnetic radiation due to dielectric losses;

- the presence of structural elements that form Rayleigh structures and zones where waves are added in antiphase;

- realization of the minimal difference of wave resistances on the boundary between the nanostructured composite RAMs and air. 
The study performed by the authors has shown that the abovementioned conditions could be realized when introducing carbon nanotubes and nanofibers into the polymer matrix.

In [6] application of properties of nonlinear, amplifying, active and controlled complex media for the creation of thin broadband absorbers was considered. It was shown that the development of absorbers of this type was an alternative to commonly used materials with high values of magnetic and dielectric permeability as radiation absorbent coatings and that this would eliminate limitations of passive absorbers.

\section{Modern technologies for improving the quality of components and construction of MRCs}

Nowadays, the main part of the MRC hulls (in particular, pilotless aerial vehicles) is made of polymer composite materials (PCM). When developing MRCs, the world's leading manufacturers use the following state-of-the-art technologies:

- transgenic biopolymers are applied in development of ultralight, high-strength and elastic materials with high visibility characteristics for MRC cases [8];

- carbon nanotubes are used in electronic MRC systems and in composites to reduce electromagnetic radiation [14];

- microelectronic mechanical systems that combine microelectronic and micromechanical elements [20];

- hydrogen engines, which can significantly reduce the level of noise [4];

- intellegent materials that change their shape or perform some given function under external actions [2];

- intelligent composites or specially structured systems consisting of subsystems for reading a signal (action), its processing, response generation, and of mechanisms of feedback, self-diagnosis and self-recovery;

- self-healing materials: polymers, ceramics, metals and graphene-based materials [1];

- magnetic nanoparticles, which are a hop in development of storage devices; they expand significantly computing capabilities of robotic and umanned systems; the potential of the technology, which is achieved by using nanoparticles with a size of 10 to $20 \mathrm{~nm}$ is $400 \mathrm{Gbps} / \mathrm{cm}^{2}$.

In the USA, a fiber with a thin-film coating in which solar cells are integrated is being developed. Such fiber is planned to be used for the manufacture of structural fabric capable to generate electricity for MRCs and for its payload. If this project completes successfully, developers will receive a new design material that will create light small MRCs with a long autonomy time [11].

Strategic directions for the MRC creation should be:

- development of materials for the case and engine;

- improvement of visibility reduction technologies;

- development of polymer composite materials on carbon and glass fillers having a unique set of properties: high elasticstrength characteristics (strength up to $2.5 \mathrm{GPa}$, modulus of elasticity up to $160 \mathrm{GPa}$ ), low cost production, high radiation transparency, low moisture absorption and high resistance to shock loads (strength of carbon fiber in compression after impact in more than $200 \mathrm{MPa}$ ).

It should be mentioned that the development and production of a modern MRC is not the problem of machine, ship or aircraft construction in their traditional sense. A distinctive feature of MRC is its focus on the task to perform. In this case, the device performs an important, but one of many functions - transportation, and the key word hear is "complex".

For the production of MRs of a new generation, it is necessary to take the following actions for improving the quality of components and design:

- development and production of modern construction materials: composite, with nanocoatings, welded, corrosionresistant aluminum-lithium alloys of low density, welding technologies in solid phase [9];

- physical integration of the onboard equipment and various systems in the MRC;
- improvement of modern computer technologies, including multiprocessor systems for data collection, processing and storage;

- development of automatic control systems connected to information transmission, encryption and data compression systems;

- development of technologies of highly stable and noiseimmune means of communication;

- improvement of remote technologies for probing the environment (radar, optoelectronic systems, multifunctional sensors);

- development and application of energy technologies, use of alternative energy sources: ultra-large capacity batteries, solar energy, large-capacity fuel cells;

- application of GNSS satellite navigation tools and systems and geographic information systems to provide accurate positioning of MRCs;

- improving the technology of image processing and pattern recognition;

- improvement of human-machine interface technology and artificial intelligence systems;

- development of technology of high-speed control systems to provide stability and controllability of MRCs in order to eliminate different negative effects and stochastic loads during the movement;

- creation of a power plant with a high efficiency to provide energy capacity and specific power as well as maximum duration and secrecy of movement, which requires the use of new materials and technologies;

- development of an improved visibility reduction technology, that is implementation of a special MRC design and application of radiation-absorbent, radiation-scattering and adaptive materials and coatings in the MRC design.

\section{Methods of detecting low-observable objects}

As can be seen from [19], application of architectural protection of the mobile object and radiation-absorbent material provides reduction of the effective reflective surface of an object by 10 times or more. Whereas intensity of the received radar signal is a function of the distance to the object in the fourth degree [15], it reduces the detection range by $1.5 \div 2$ times.

Thus, the low-observable objects have the following features:

- the level of a reflected radar signal in the direction of a receiving antenna is reduced significantly due to radiation absorption and reflection in other directions, resulting in a decrease in signal-to-noise ratio;

- reflection of the radar signal from flat surfaces of relatively large size occurs with formation of a narrow pattern and the presence of side petals;

- reduction of a distance to the radio horizon by choosing appropriate architectural forms of the low-observable object.

From the above mentioned, we can identify the following areas for developing methods of detecting low-observable objects in radiolocation:

- development of methods for detecting objects by a direct reflected radar signal coming to a receiving antenna of the radar;

- increasing the distance to the radio horizont for stable detection of objects;

- establishment of a radar surveillance system so that the radar signal reflected from the object can be used for detection.

According to the first direction, it is necessary to determine the power $P_{D}$ of the received reflected signal from the radar range equation considering parameters of the radar for a common antenna for transmission and reception:

$$
P_{D}=\frac{P_{B} G_{A} S_{A} \sigma}{16 \pi^{2} D^{4}}=\frac{P_{B} S_{A}^{2} \sigma}{4 \pi D^{4} \lambda^{2}},
$$


where $\frac{P_{B} G_{A}}{4 \pi D^{2}}-$ is the radiation power of the probing pulse at the distance $\mathrm{D}$ from the radar with the radiant power of the radar $P_{B}$; $G_{A}=\frac{4 \pi S_{A}}{\lambda^{2}}-$ is the antenna gain factor; $\sigma-$ is the effective scattering area for the inconspicuous object; $S_{A}-$ is the effective area of antenna aperture; $\lambda-$ is the wavelength at which the probe pulse is radiated.

Thus, reducing the effective scattering area of an lowobservable object results in a proportional reduction in the power of the received reflected signal. The influence of this factor can be reduced technically by increasing the power of the probe pulse of the transmitter, increasing the sensitivity of the receiver, as well as choosing the optimal antenna design.

Since reducing the effective scattering area of an inconspicuous object decreases the signal-to-noise ratio of a receiver, the effectiveness of detecting low-observable objects depends on methods and algorithms used to process radar information.

Consider methods to improve the efficiency of detection based on hardware. An obvious method is increasing the energy of the probing signal of the radar by increasing the pulse power and its radiation time. But, it is difficult to implement. There are currently no appropriate technical facilities to increase tenfold the energy of the probing signal of the radar by increasing the pulse power, while increasing the duration of the probing pulse $\tau_{P P}$ will lead to a deterioration in the radar resolution at a distance $\Delta D=0.5 c \tau_{P P}$, where $c$ is the speed of light.

The real way to increase the energy is to radiate not one but several pulses, which differ in code, during the probing period. This allows to get rid of ambiguity when determining the range of the received signal for a number of pulses in the packet without slowing down the survey. This method was implemented in [19], where a coherently built pulse radar using signals with intra-pulse phase manipulation was proposed.

The energy of a received signal can also be increased by increasing the number of reflected signals in the packet, that is the accumulation time of reflected signals. However, implementation of such an approach may lead to a slowdown in the controlled area survey and, consequently, requires more radars. To eliminate this shortcoming, in [21] a modification of this approach is proposed, at which there is an increase in the signal-to-noise ratio with almost no increase in the reflected signal energy. Also, the method performs compression of primary radar information without information loss, which is especially important because the processing of radar information must be performed in real time.

As can be seen from the basic radar equation (1), the power of the received reflected signal $P_{D}$ is proportional to the square of the effective area of the antenna aperture $S_{A}$ and depends linearly on the effective scattering area of the inconspicuous object. Therefore, the effect of reducing the effective scattering area of an inconspicuous object can be significantly offset by developing or selecting an appropriate antenna design. It should be noted that only a systematic approach to the selection of antenna design will be effective. This approach considers the increase in the energy of reflected pulses due to increase in the signal-to-noise ratio caused by the antenna pattern opening.

Therefore, we can conclude that only with a systematic approach to selection and development of technical facilities, and with appropriate methods and algorithms for processing radar signals operating at low signal-to-noise ratios the effects of stealth technologies based on reducing the reflected signal level can be significantly neutralized and the probability of detecting an low-observable object can be increased.

The distance to the radio horizont depends only on the height of the antenna and the height of the object. Therefore, when reducing the height of the object, it is necessary to increase the lift of the radar station antenna, which depends on the tasks performed by the station [16]:

$$
D_{L S} \cong 4.12\left(\sqrt{h_{A}}+\sqrt{h_{T}}\right),
$$

where $D_{L S}-$ is the line of sight, $\mathrm{km} ; h_{A}-$ is the height the electric center of the antenna, $\mathrm{m} ; h_{T}-$ is the height of a target, $\mathrm{m}$.

Thus, reducing the height of the target from $3 \mathrm{~m}$ to $1.5 \mathrm{~m}$ with the constant height of the electrical center of the antenna reduces the range of direct visibility by $2 \mathrm{~km}$. On the other hand, for continuous monitoring the area of a width up to $200 \mathrm{~km}$ at a minimum target height of $1 \mathrm{~m}$, it is necessary to raise the antenna to a height of at least $2300 \mathrm{~m}$, which is possible only when placing the antenna or radar on an aircraft. Application of air-based radars depends on solving problems of dynamically complex operating conditions and on methods and algorithms for detecting objects against the background of signals reflected from the earth's or water's surface.

It should be mentioned that irradiating the object at an angle to the horizontal plane changes the effective scattering area, which can increase the efficiency of low-observable object detection. In addition, it is possible to detect objects by their interaction with the aquatic environment (waves that diverge behind the object, turbulence of surface layers of water, excitation of wave processes in water, changes in physicochemical properties of water, etc.). However, at present, these processes are insufficiently studied in terms of radar visibility, which does not allow them to be fully used in the inconspicuous object detection.

Multi-position radars in the mode of cooperative work are used to detect objects of stealth technology by a probe signal reflected in another direction. A special case of the multi-position radar is a two-position (spaced) active location system with one transmitter (bistatic system). The cooperative reception of the reflected signals implies the use of the secondary radiation of the object, which is probed from any one position, at different positions.

\section{Conclusions}

The state-of-the-art technologies used by the world's leading manufacturers in the development of low-visibility MRCs have been outlined, as well as perspective measures aimed at improving the quality of components and structures of such facilities.

Methods of detecting objects using stealth technologies have been considered, and it has been shown that only due to the system approach it was possible to compensate for reduction of the effective scattering surface of low-observable objects by radar technical facilities.

Since the invisibility of the object results in a decrease in the signal-to-noise ratio, this parameter must be maximized in the radar receiver.

It has been shown that the main method of increasing the range to the radio horizont is the application of air-based radar. To organize a common operation of several radars at detection of low-observable objects, methods of detecting objects by traces of their interaction with environment (in particular, water) are quite perspective.

The problem of the detecting objects of stealth technology can be solved only with a systematic approach to implementation of all considered radar technical facilities and with a development of methods and algorithms for detecting objects that operate at low signal-to-noise ratio.

\section{Acknowledgments}

The work is performed on the results of studies based on research work "Methods and devices for forming and processing chaotic signals, access control and positioning in robotic and infocommunication systems" and was supported by the Ministry of Education and Science of Ukraine, grant No. $0121 \mathrm{U} 109722$. 


\section{References}

[1] Alekhin M., Klabukov I., Musienko S.: Smart Intelligent Aircraft Materials and Microsystems Technology. The future of the industry. Materials 4th ISTC. MFTI, Moscow 2012, 189-221 [http://doi.org/10.2139/ssrn.2456695].

[2] Bobovich B. B.: Non-metallic materials of construction. MGIU, Moscow 2009.

[3] Costa F. et al.: Ultra-thin absorbers for ultra-high frequency RFID systems. IEEE Antennas and Propagation Society International Symposium (APSURSI), 2013, 1500-1501 [http://doi.org/10.1109/APS.2013.6711409].

[4] Furrutter M. K., Meyer J.: Small fuel cell powering an unmanned aerial vehicle. AFRICON 2009, 1-6 [http://doi.org/10.1109/AFRCON.2009.5308096]

[5] Garyn B. M., Dyakonova O. A., Kazantsev Yu. N.: Physical properties of resistive filaments and structures based on them in the microwave range. Journal of Technical Physics 69(1), 1999, 104-108.

[6] Guo T., Argyropoulos C.: Nonlinear and Amplification Response with Asymmetric Graphene-based Coherent Perfect Absorbers. IEEE International Symposium on Antennas and Propagation and North American Radio Science Meeting 2020, 727-728 [http://doi.org/10.1109/IEEECONF35879.2020.9330288].

[7] Hu P., Bao Q., Chen Z.: Target Detection and Localization Using NonCooperative Frequency Agile Phased Array Radar Illuminator. IEEE Access 7 , 2019, 111277-111286 [http://doi.org/10.1109/ACCESS.2019.2934754]

[8] Joshi S. A. et al.: Wireless controlled military combat robot system. 2nd International Conference on Communication and Electronics Systems (ICCES), 2017, 712-715 [http://doi.org/10.1109/CESYS.2017.8321173].

[9] Kablov E. N.: Strategic directions for the development of materials and technologies for their processing for the period until 2030. Aviation materials and technologies 8, 2012, 7-17.

[10] Khan M. A. H. et al.: Accelerated Stress Tests and Statistical Reliability Analysis of Metal-Oxide/GaN Nanostructured Sensor Devices. IEEE Transactions on Device and Materials Reliability 20(4), 2020, 742-747 [http://doi.org/10.1109/TDMR.2020.3028786].

\begin{abstract}
D.Sc. Andrii Rudyk
e-mail: a.v.rudyk@nuwm.edu.ua

Professor of Automation, electrical engineering and computer integrated technologies Department, National University of Water and Environmental Engineering, Rivne, Ukraine.

The main scientific direction - development of methods and devices for measuring motion parameters of mobile robots. Author over 180 scientific papers, including 12 patents.
\end{abstract}

http://orcid.org/0000-0002-5981-3124

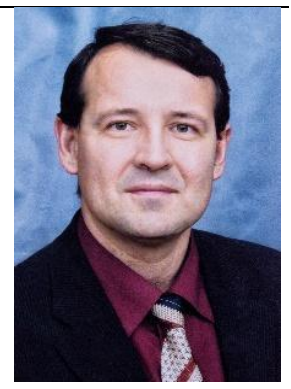

\section{D.Sc. Andriy Semenov}

e-mail: semenov.a.o@vntu.edu.ua

Doctor of science in Engineering, Full Professor, Professor at the Department of Radio-Frequency Engineering, Faculty for Infocommunications, Radioelectronics and Nanosystems, Vinnytsia National Technical University, Vinnytsia, Ukraine.

His areas of research interest include Methods and devices for forming, processing and measuring signals of information and communication systems. Author over 270 scientific papers, including 45 patents.

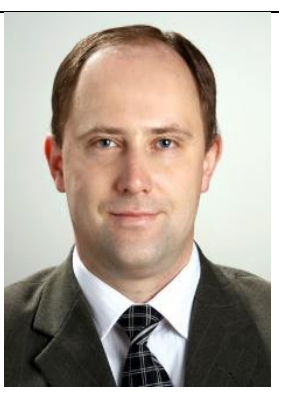

http://orcid.org/0000-0001-9580-6602
[11] Le K. Q. et al.: Dielectric Antireflection Fiber Arrays for Absorption Enhancement in Thin-Film Organic Tandem Solar Cells. IEEE Journal of Selected Topics in Quantum Electronics 22(1), 2016, 1-6 [http://doi.org/10.1109/JSTQE.2015.2447551].

[12] Li X., Wei P., Wei Z. J., Guosong L., Ping W.: Research on Security Issues of Military Internet of Things. 17th International Computer Conference on Wavelet Active Media Technology and Information Processing (ICCWAMTIP), 2020, 399-403 [http://doi.org/10.1109/ICCWAMTIP51612.2020.9317401].

[13] Lisý K. et al.: Measurement and Evaluation of Dielectric, Magnetic and Microwave Absorbing Properties of Carbonyl Iron Loaded Polymer Composites. 12th International Conference on Measurement, 2019, 240-243, [http://doi.org/10.23919/MEASUREMENT47340.2019.8779863].

[14] Muradyan V. E., Sokolov E. A., Babenko S. D., Moravskii A. P.: Dielectric properties of composites modified with carbon nanostructures in the microwave range. Journal of Technical Physics 80(2), 2010, 83-87.

[15] Skolnik M. I.: Radar Handbook, Third Edition. McGraw-Hill Education, 2008.

[16] Tyapkin V. N.: Fundamentals of building radar stations for radio engineering troops. Siberian Federal University, Krasnoyarsk 2011.

[17] Wallace J. L.: Broadband Magnetic Microwave Absorbers: Fundamental Limitations. IEEE Trans. Magn. 29(3), 1993, 4209-4214.

[18] Wong E. Y., Sambaluk N. M.: Disruptive innovations to help protect against future threats. International Conference on Cyber Conflict (CyCon U.S.), 2016, 1-5 [http://doi.org/10.1109/CYCONUS.2016.7836629].

[19] Yuan J. et al.: Potential for Application of Retroreflective Materials instead of Highly Reflective Materials for Urban Heat Island Mitigation. Urban Studies Research 10, 2016 [http://doi.org/10.1155/2016/3626294].

[20] Zhang K., Zhao N., Wang Y.H.: Closed-Loop Nuclear Magnetic Resonance Gyroscope Based on Rb-Xe. Sci Rep 10, 2020 [http://doi.org/10.1038/s41598020-59088-y].

[21] Zhao Z., Niu Y., Ma Z., Ji X.: A fast stealth trajectory planning algorithm for stealth UAV to fly in multi-radar network. IEEE International Conference on Real-time Computing and Robotics (RCAR), 2016, 549-554 [http://doi.org/10.1109/RCAR.2016.7784089].

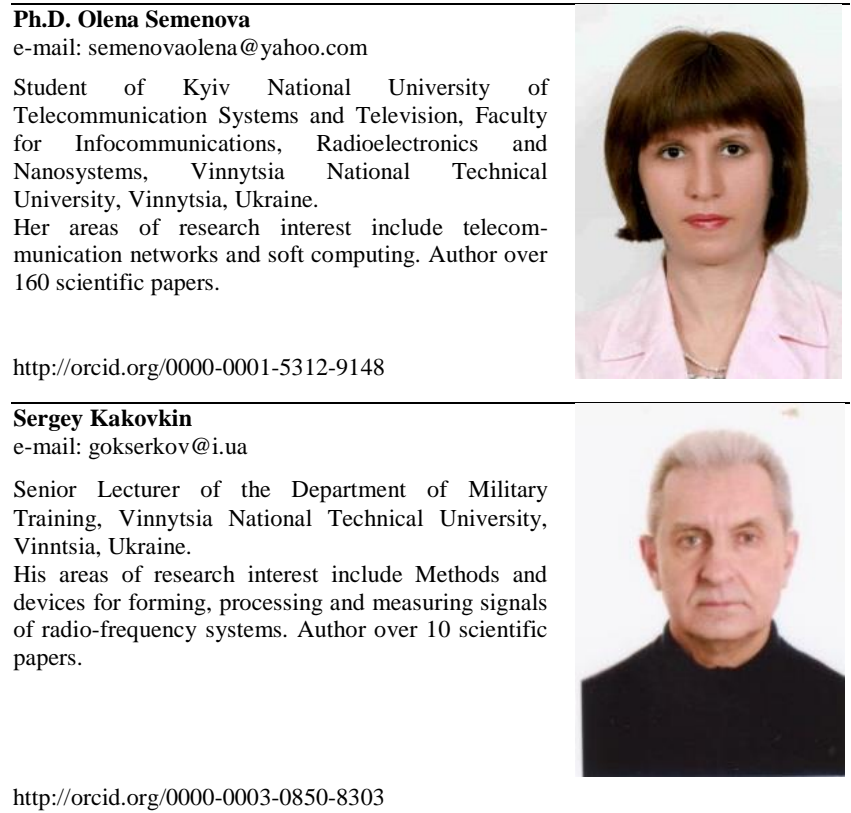

otrzymanofreceived: 26.07 .2021

przyjęto do druku/accepted: 15.09 .2021 